\title{
Incidental findings in the thyroid gland on computed tomography images of the oral and maxillofacial region
}

\author{
ABDULLAH KHASAWNEH ${ }^{1}$, YOHEI TAKESHITA ${ }^{1}$, MIKI HISATOMI ${ }^{2}$, TOSHIYUKI KAWAZU $^{1}$, MARIKO FUJITA ${ }^{3}$, \\ SHUNSUKE OKADA $^{1}$, YURI NAMBA ${ }^{2}$, YUDAI SHIMIZU ${ }^{1}$, YOSHINOBU YANAGI ${ }^{4}$ and JUNICHI ASAUMI ${ }^{1-3}$ \\ ${ }^{1}$ Department of Oral and Maxillofacial Radiology, Okayama University Graduate School of Medicine, \\ Dentistry and Pharmaceutical Sciences; ${ }^{2}$ Department of Oral Diagnosis and Dentomaxillofacial Radiology, \\ Okayama University Hospital; ${ }^{3}$ Dental Comprehensive Diagnosis Room, Okayama University Hospital; \\ ${ }^{4}$ Department of Dental Informatics, Okayama University Graduate School of Medicine, \\ Dentistry and Pharmaceutical Sciences, Okayama 700-8558, Japan
}

Received August 30, 2019; Accepted November 25, 2019

DOI: $10.3892 / \mathrm{ol} .2020 .11298$

\begin{abstract}
The numbers of abnormal findings incidentally detected in adjacent regions are increasing with advances in imaging modalities. The present study aimed to examine the prevalence and characteristics of incidental findings in the thyroid gland on computed tomography (CT) images of the oral and maxillofacial region. CT scans of the oral and maxillofacial region in patients obtained between January 2012 and December 2016 were retrospectively reviewed. Images that revealed incidental findings in the thyroid gland, including nodules, were recorded, together with the sizes and characteristics of the findings. The Japan Association of Breast and Thyroid Sonology (JABTS) guidelines were used for classification. The rate of descriptions of these findings in the radiographic interpretation reports were also examined. Of the 1,135 patients examined, $326(28.7 \%)$ had several types of incidental findings. In particular, 169 (14.9\%) of the 1,135 patients had nodules $>5 \mathrm{~mm}$ in diameter, for which further careful examination is recommended in the JABTS guideline. The description rate for nodules $>5 \mathrm{~mm}$ in diameter in the radiographic interpretation reports was $30.8 \%$ (52/169 patients), of whom $17.3 \%$ ( $9 / 52$ patients) were referred to the endocrinology
\end{abstract}

Correspondence to: Dr Yohei Takeshita, Department of Oral and Maxillofacial Radiology, Okayama University Graduate School of Medicine, Dentistry and Pharmaceutical Sciences, 2-5-1 Shikata-cho, Kita-ku, Okayama 700-8558, Japan

E-mail: takeshita@okayama-u.ac.jp

Abbreviations: CT, computed tomography; JABTS, The Japan Association of Breast and Thyroid Sonology; MRI, magnetic resonance imaging; ITN, incidental thyroid nodule; US, ultrasonography; FNAC, fine-needle aspiration cytology; PET-CT, positron emission tomography-computed tomography; ${ }^{18} \mathrm{~F}-\mathrm{FDG},{ }^{18} \mathrm{~F}$-fluorodeoxyglucose

Key words: incidental finding, computed tomography, thyroid gland, thyroid nodule, diagnosis department for further careful examination. Incidental findings in the thyroid gland were relatively common on CT images of the oral and maxillofacial region. Oral radiologists tend to focus specifically on the oral and maxillofacial region during diagnosis on oral and maxillofacial CT images, but should pay the same careful attention to observe adjacent regions, such as the thyroid gland.

\section{Introduction}

In the oral and maxillofacial region, diagnosis of lesions or structures has long been performed on the basis of plain radiographs such as intraoral radiographs and panoramic radiographs. In recent years, with the development of imaging modalities, there has been increased identification on computed tomography (CT) and magnetic resonance imaging (MRI) images, as advanced modalities $(1,2)$. In particular, CT machines are maintained at many facilities, making it possible to achieve more detailed diagnoses by CT examination immediately after obtaining information on plain radiographs of the oral and maxillofacial region (3-5). The CT scan time is becoming faster and large amounts of information can be obtained in a short time. Imaging of the oral and maxillofacial region often includes part of the base of the brain, the thyroid gland, and the apex of the lung. Consequently, oral radiologists need to take care in observing adjacent regions in the images. The thyroid gland should certainly be observed because its entirety is frequently included in CT images of the oral and maxillofacial region.

The numbers of abnormal findings incidentally detected in adjacent regions are increasing with advances in imaging modalities (6-9). Such findings are often observed on CT images with extended fields of view. However, because radiologists sometimes overlook these findings in images or doctors can fail to confirm radiographic interpretation reports, this issue has become an important social problem. In particular, lesions of the thyroid gland can be found incidentally on CT images of the oral and maxillofacial region. An incidental thyroid nodule (ITN) is an unsuspected asymptomatic thyroid lesion 
observed in an imaging study or during an operation unrelated to the thyroid gland (10-14). ITNs are most commonly detected by ultrasound procedures, followed by CT scans (10-12). Although most ITNs are benign (11), they remain clinically important because of their malignant potential (15). Thus, it is important to detect and report these nodules with possible malignancy, even if the lesions are small.

The present study aimed to examine the prevalence and characteristics of incidental findings of the thyroid gland on oral and maxillofacial CT images within the patient database of our institution. The rate of descriptions of such findings in radiographic interpretation reports by oral radiologists, and whether any consultation requests were made by doctors were also examined.

\section{Materials and methods}

Study subjects. We retrospectively reviewed CT scans of the oral and maxillofacial region in patients taken at our institution from January 2012 to December 2016. The study subjects were patients who underwent CT scans for the first time during the indicated period and had images that showed the thyroid gland in its entirety. Only those with no prior history of thyroid gland disease were included for evaluation of incidental findings.

Evaluation of ITNs and radiographic interpretation reports. The following patient information was obtained: Sex; age; incidental finding; interpretation report. Regarding incidental findings, images that showed ITNs or other abnormalities (calcification, enlargement, atrophy) were noted, and the sizes and characteristics of the findings were recorded.

Ultrasonography (US) is used for the diagnosis of thyroid gland disease because it is simple, non-invasive, and useful compared with other examinations. The Japan Association of Breast and Thyroid Sonology (JABTS) guideline was prepared for US diagnosis of thyroid gland disease, and its categories of lesions by size are shown in Table I (16). We decided to use this guideline for the evaluation of ITNs because it provides suitable standards for screening on CT images. According to the guideline, fine-needle aspiration cytology (FNAC) or follow-up is recommended when ITNs exceed $5 \mathrm{~mm}$ in diameter because the possibility of malignancy cannot be excluded Therefore, we examined the rate of whether such incidental findings were described in the radiographic interpretation reports by oral radiologists, and whether any consultation requests were made by doctors.

CT scans. Images were taken using five types of CT machines (Aquilion 16: Canon Medical Systems Corporation, Tochigi, Japan; Aquilion 64: Canon Medical Systems Corporation; Aquilion One: Canon Medical Systems Corporation; Discovery CT750 HD: GE Healthcare; SOMATOM Definition Flash: Siemens). CT scans were obtained with the following parameters: Field of view: $12.9 \times 12.9$ to $32 \times 32 \mathrm{~cm}$; tube voltage: 120-140 kV; tube current: 150-500 mA.

Statistical analysis. Statistical analysis was undertaken by calculating percentages of particular cases and classifications over the total number of eligible scanned patients.

\section{Results}

Clinical features. A total of 3159 patients underwent CT scans for the first time during the research period, and images for 1,147 patients showed the thyroid gland in its entirety. Twelve patients were excluded because they had history of thyroid disease. Therefore, CT images of 1,135 patients were evaluated in this study.

The 1,135 patients comprised 551 men and 584 women, with a mean age of 56.4 years (range, 0.3-98 years). Several kinds of incidental findings in the thyroid gland, including ITNs, were observed in 100 of 551 men (18.1\%) and 226 of 584 women (38.7\%) (Fig. 1). The prevalence of these findings was 2-fold higher in women compared with men.

Classification and characteristics of ITNs. For 326 of 1135 patients $(28.7 \%)$ with incidental findings such as ITNs (Fig. 2A), their images were evaluated and classified according to the JABTS guideline. ITNs with abnormalities such as calcification, enlargement, and atrophy were included as 'ITNs' in the classification. Of the 326 patients, $112(34.4 \%)$ had ITNs $\leq 5 \mathrm{~mm}$ in diameter, $118(36.2 \%)$ had ITNs $>5 \mathrm{~mm}$ to $\leq 10 \mathrm{~mm}, 43(13.2 \%)$ had ITNs $>10 \mathrm{~mm}$ to $\leq 20 \mathrm{~mm}, 8(2.4 \%)$ had ITNs $>20 \mathrm{~mm}$, and $45(13.8 \%)$ had only abnormalities of gland size or calcification (Fig. 2B). As a result, 169 patients among all 1,135 patients (14.9\%) whose images contained the thyroid gland in its entirety had ITNs exceeding $5 \mathrm{~mm}$ in diameter, for which further careful examination such as FNAC or follow-up is recommended according to the JABTS guideline because the possibility of malignancy cannot be excluded.

Descriptions in the radiographic interpretation reports and consultation requests. The rate of descriptions of incidental findings for ITNs exceeding $5 \mathrm{~mm}$ in diameter in the radiographic interpretation reports was $30.8 \%$ (52 of 169 patients) (Fig. 3A), of whom $17.3 \%$ (9 of 52 patients) were referred to the endocrinology department for further careful examination (Fig. 3B).

Case report. We present a case of an incidental finding in the thyroid gland that was observed on oral and maxillofacial CT images, thereby facilitating further treatment after it was described in the radiographic interpretation report.

In August 2014, a 71-year-old woman visited our institution with the complaint of a mass in the right buccal mucosa. An incisional biopsy of the right buccal mucosa was performed under suspicion of papilloma, but squamous cell carcinoma was suspected in the pathological diagnosis. A contrast-enhanced CT evaluation was performed for further evaluation in September 2014. Although there was no metastasis in the lymph nodes, a mass of $\sim 30 \mathrm{~mm}$ in diameter with calcification was incidentally observed in the left lobe of the thyroid gland, suggesting an ITN (Fig. 4). Thus, further examination was recommended in the radiographic interpretation report. On positron emission tomography-computed tomography (PET-CT) with ${ }^{18} \mathrm{~F}$-fluorodeoxyglucose $\left({ }^{18} \mathrm{~F}\right.$-FDG) for further evaluation of whole body including the right buccal mucosa, ${ }^{18} \mathrm{~F}$-FDG uptake was noted in the left lobe of the thyroid gland with a maximum standardized uptake value of 3.26 (Fig. 5). For further evaluation of the ITN, the patient was referred to the otolaryngology department in October 2014. US and 
Table I. Size categories of thyroid gland nodules based on the Japan Association of Breast and Thyroid Sonology guidelines.

Evaluation criteria for thyroid gland nodules

\begin{tabular}{lll}
\cline { 2 - 3 } Size category & \multicolumn{1}{c}{ Cystic nodule } & \multicolumn{1}{c}{ Solid nodule } \\
\hline$\leq 5 \mathrm{~mm}$ & Follow-up & Follow-up \\
$>5 \mathrm{~mm}$ to $\leq 10 \mathrm{~mm}$ & Follow-up & FNAC if shows malignant findings \\
$>10 \mathrm{~mm}$ to $\leq 20 \mathrm{~mm}$ & FNAC if contains solid parts & FNAC if shows malignant findings \\
$>20 \mathrm{~mm}$ & FNAC & FNAC
\end{tabular}

FNAC, fine-needle aspiration cytology.
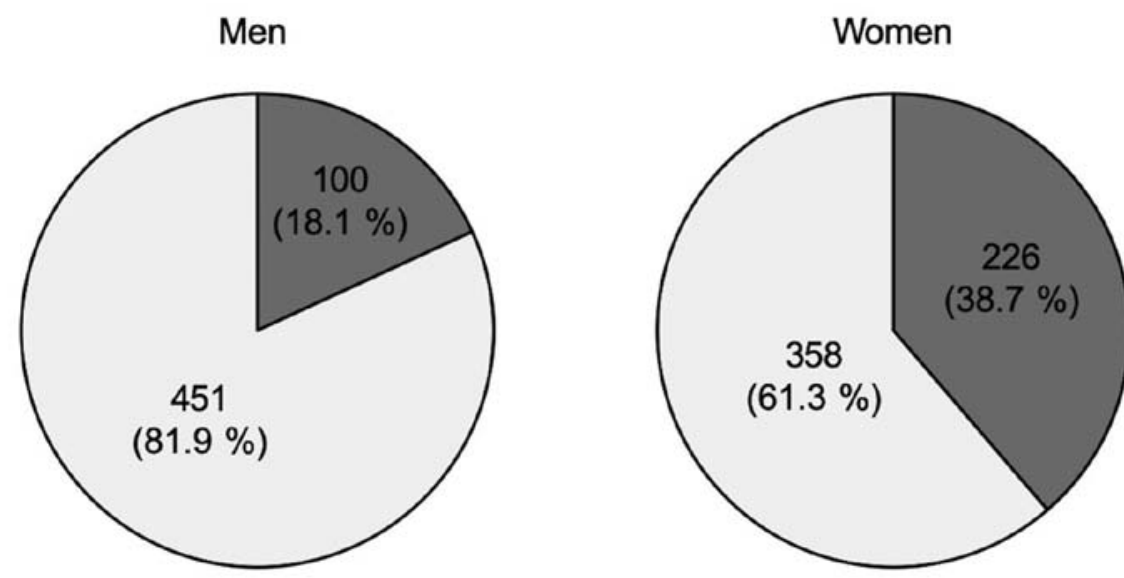

口Incidental findings $\square$ None

Figure 1. Prevalence of incidental findings in the thyroid gland according to sex. Incidental findings were 2 -fold more common in women than in men.

FNAC were subsequently performed, and papillary carcinoma of the thyroid gland was suspected. The ITN in the left lobe of the thyroid gland was surgically excised under general anesthesia, with simultaneous performance of a prophylactic left neck dissection with lymph nodes. On postoperative histopathological examination, the diagnosis was adenomatous goiter, and consequently not malignant.

\section{Discussion}

Plain radiographs such as intraoral radiographs and panoramic radiographs are often used for screening in the oral and maxillofacial region. A previous report described the significance of a $6.1 \%$ detection rate for incidental lesions on panoramic radiographs during relatively early childhood (17). The research further indicated that early treatment of such lesions could avoid maxillofacial deformities and other complications. Panoramic radiographs are also available for screening of osteoporosis or calcified atheroma in the common carotid artery (18). Descriptions of these findings in radiographic interpretation reports are very important because they can lead to the prevention of systemic diseases.

With the development of imaging modalities in recent years, there has been an increase in the identification of incidental lesions on images obtained by CT and MRI, as advanced imaging modalities (6-9,19-21). In particular, CT machines are maintained at many facilities, and it is possible to obtain more detailed diagnoses by $\mathrm{CT}$ immediately after lesions are suspected on plain radiographs of the oral and maxillofacial region. The field of view in the oral and maxillofacial region often includes a region from the base of the brain to the apex of the lung, and thus oral radiologists need to take care to observe adjacent regions in the images. Indeed, many incidental findings have been described in previous reports $(6-9,19-21)$. The thyroid gland should be focused upon because its entirety is frequently included in CT images of the oral and maxillofacial region. Because it is essential to understand both normal and abnormal findings, we focused on the thyroid gland in the present study.

Diagnosis of thyroid gland disease is often performed by US because this modality is easy, non-invasive, and useful for evaluation of internal properties compared with other examinations (22-26). CT images are helpful for the detection of incidental thyroid lesions and subsequent US examinations. The prevalence of incidental lesions of the thyroid gland was approximately 10 to $40 \%$ in a previous US study (11). Most of the incidentally detected lesions were benign, but the risk of malignancy ranged from 1.5 to $17 \%$ (11). Several identified associations have led to the establishment of guidelines for management of ITNs detected by different imaging modalities (27-30). Of interest to us was the JABTS guideline shown in Table I. Although this guideline was developed for US diagnosis of thyroid gland disease, it provides detailed categorization of lesions by size. Thus, we considered that this guideline could be used as a standard for screening on CT images. 
A $\quad$ B

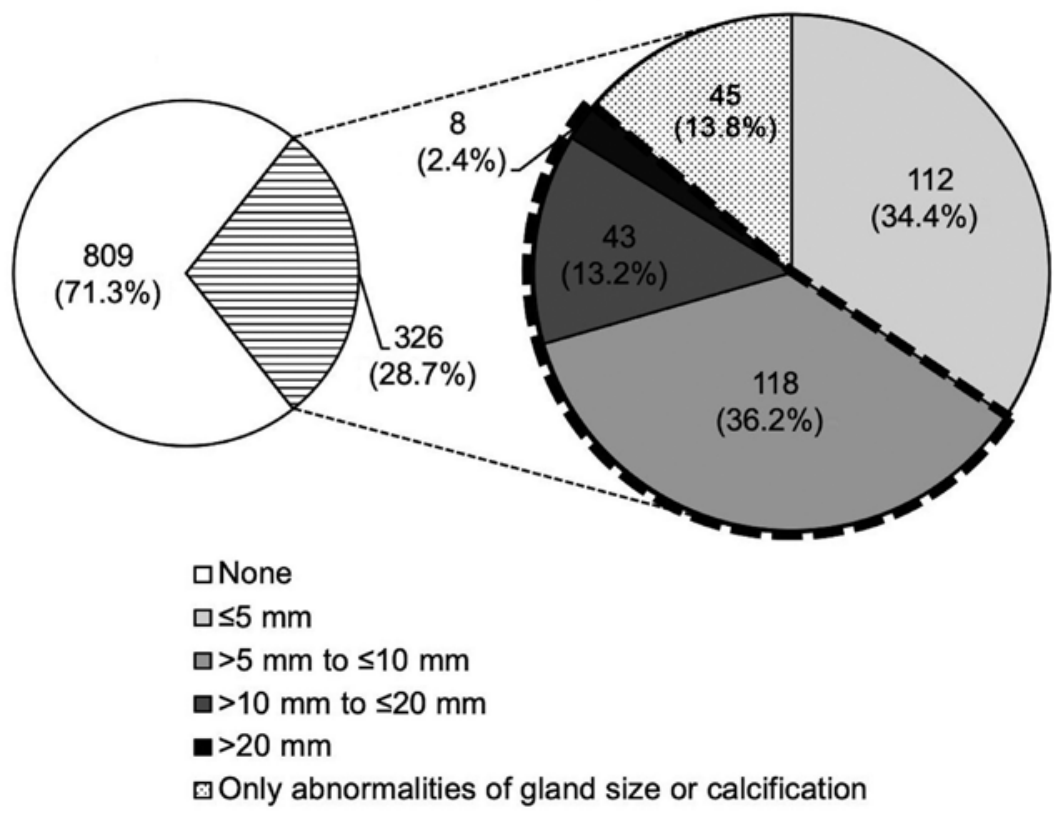

Figure 2. Prevalence and classification of incidental findings in the thyroid gland. (A) Prevalence of incidental findings in the thyroid gland. (B) Classification of incidental findings in the thyroid gland according to the JABTS guidelines. The region surrounded by the dotted line shows incidental thyroid nodules exceeding $5 \mathrm{~mm}$ in diameter, for which further careful examination is recommended in the JABTS guidelines. JABTS, The Japan Association of Breast and Thyroid Sonology.

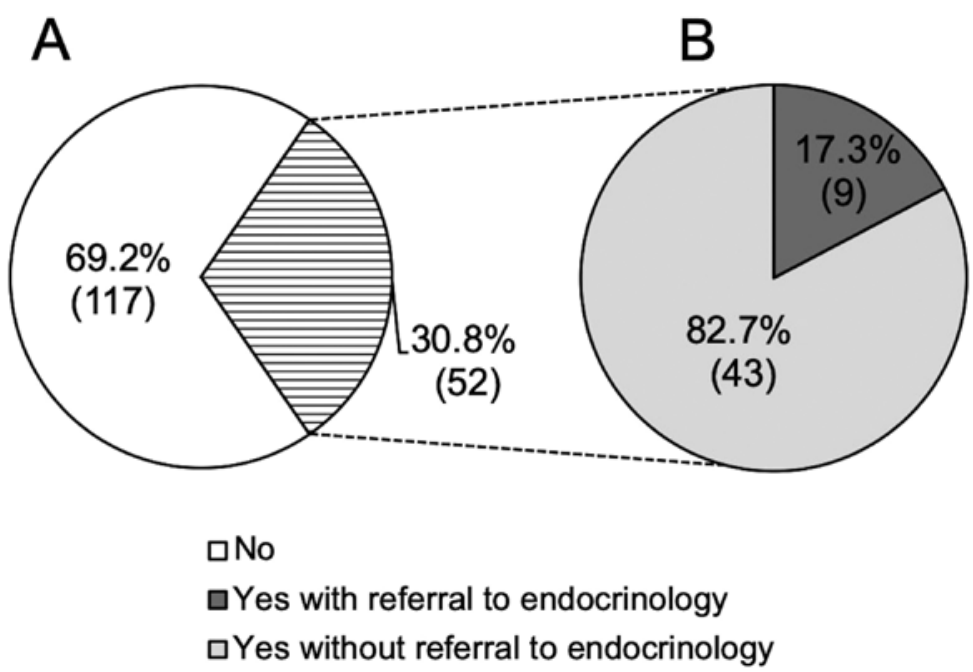

Figure 3. Rates of descriptions and referrals for ITNs exceeding $5 \mathrm{~mm}$ in diameter. (A) Rate of descriptions for ITNs exceeding $5 \mathrm{~mm}$ in diameter in the radiographic interpretation reports. (B) Rate of patients with ITNs exceeding $5 \mathrm{~mm}$ in diameter referred to the endocrinology department. ITN, incidental thyroid nodule.

In the CT images of our 1,135 patients, the prevalence of incidental findings in the thyroid gland was $28.7 \%$. This prevalence was higher than that in a similar study by Yoon et al (11), who reported that $16.8 \%$ of patients had incidentally detected thyroid lesions. The discrepancy may arise from the difference in mean age of the patients because our patients were older than those in the study by Yoon et al (11). We also evaluated the sizes of the ITNs, and found that 169 of the 1,135 patients (14.9\%) whose images showed the thyroid gland in its entirety had ITNs that exceeded $5 \mathrm{~mm}$ in diameter. Because the possibility of malignancy cannot be excluded, ITNs of this size are recommended for further careful examination such as FNAC or follow-up in the JABTS guideline. In addition, the presence of calcification was reported to be associated with a higher risk of malignancy $(31,32)$. Previous US studies indicated that the risk of malignancy in patients with ITNs selected for FNAC was 9.2 to $13.0 \%(31,32)$. In the present study, no patients had ITNs that were histologically confirmed to be malignant. However, not all patients with ITNs underwent FNAC, and thus there may have been more patients with ITNS suggestive of malignancy or with malignancy.

Diagnosis of thyroid gland disease on CT images is insufficient and limited compared with US examinations because 

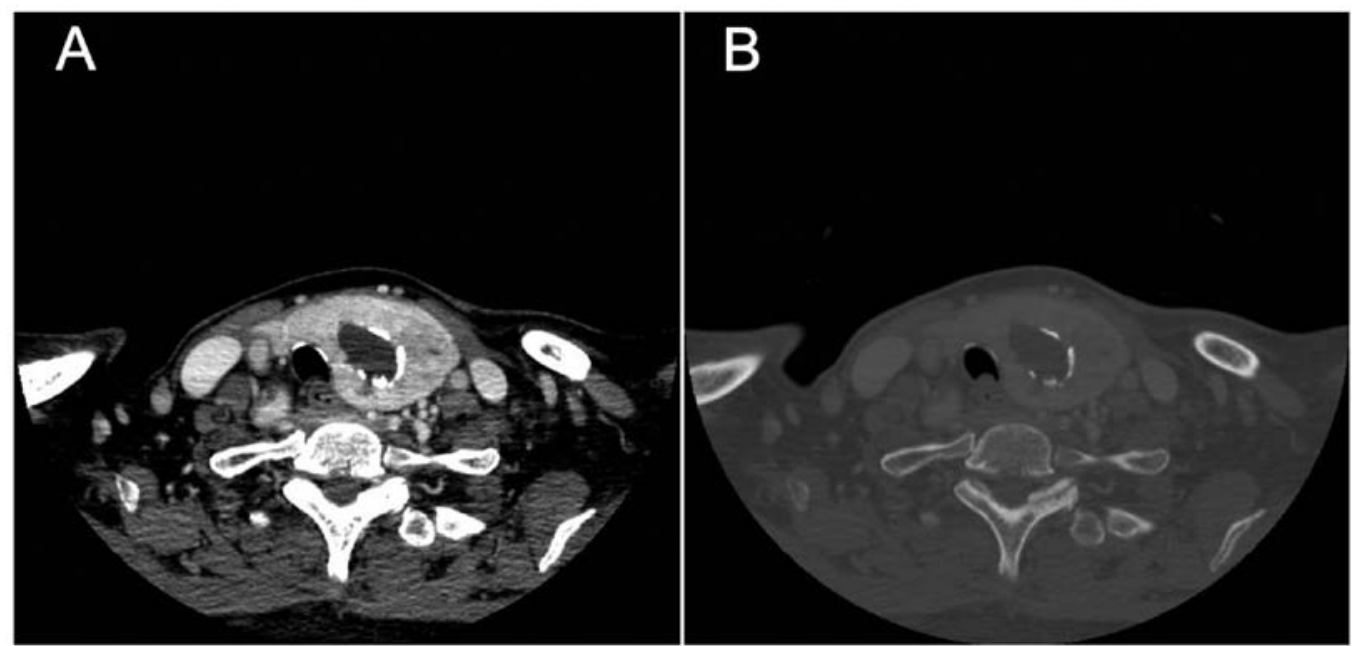

Figure 4. Contrast-enhanced computed tomography images for a patient with an incidental finding in the thyroid gland. (A) Axial image of soft tissue. A mass $\sim 30 \mathrm{~mm}$ in diameter was found in the left lobe of the thyroid gland. (B) Axial image of bone showing calcification in the mass.

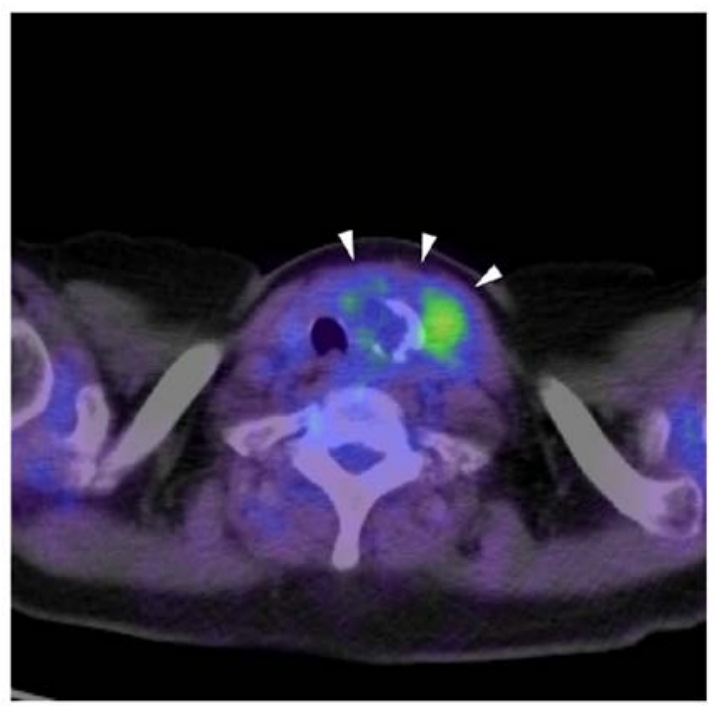

Figure 5. Positron emission tomography-computed tomography image showing ${ }^{18} \mathrm{~F}$-fluorodeoxyglucose uptake in the left lobe of the thyroid gland (white arrows). The maximum standardized uptake value was 3.26.

the images are affected by the slice thickness or partial volume effects. However, CT could be an effective evaluation method for thyroid gland screening and assistance in US examination. Therefore, oral radiologists should understand the characteristics of thyroid gland lesions and inform doctors when such incidental findings are observed on CT images. Although the ITN in the left lobe of the thyroid gland in the patient described our case report was not malignant, it was strongly suspected of malignancy in preoperative examinations. Thus, it can be concluded that the related description of this incidental finding in the radiographic interpretation report for the oral and maxillofacial CT images was very effective.

It has become an important social problem that not only do radiologists sometimes overlook incidental findings on images but also doctors can fail to confirm radiographic interpretation reports, directly leading to worse prognosis of patients and possible litigation. In the present study, the rate of descriptions for ITNs exceeding $5 \mathrm{~mm}$ in diameter in radiographic interpre- tation reports was $30.8 \%$ (52 of 169 patients). There were also several cases wherein ITNs $>5 \mathrm{~mm}$ to $\leq 10 \mathrm{~mm}$ or $>10 \mathrm{~mm}$ to $\leq 20 \mathrm{~mm}$ were overlooked in the reports. ITNs of these sizes are considered to have potential for malignancy and are not difficult to find, and thus failure to include them appears to be due to the discrepancy in the viewpoints of the attending oral radiologists. Furthermore, only $17.3 \%$ ( 9 of 52 patients) were referred to the endocrinology department for further careful examination. This may arise from unconfirmed reports, scant attention or lack of knowledge by doctors. Awareness building for doctors to carefully check radiographic interpretation reports is also needed.

In conclusion, relatively many incidental findings of the thyroid gland were observed on CT images. Oral radiologists tend to focus on the oral and maxillofacial region during diagnosis on oral and maxillofacial CT images, but should pay the same careful attention to observe adjacent regions including the thyroid gland.

\section{Acknowledgements}

The authors would like to thank Dr Alison Sherwin for editing a draft of this manuscript.

\section{Funding}

No funding was received.

\section{Availability of data and materials}

All data generated or analyzed during this study are included in this published article.

\section{Authors' contributions}

AK and YT analyzed the data and drafted the manuscript. YT and $\mathrm{MH}$ contributed to the concept and design of the work, and revised the manuscript. TK, MF, SO, YN, YS, YY and JA interpreted the data. YT played a major role in preparation of the manuscript. All authors read and approved the final manuscript. 


\section{Ethics approval and consent to participate}

The present study was approved by Okayama University Ethics Committee (approval No. 1705-006), and conducted in accordance with the Helsinki Declaration. The current study was explained to the patients who underwent $\mathrm{CT}$ scans for the first time at Okayama University hospital from January 2012 to December 2016. Patients were also able to browse a website with additional information, including an opt-out option that let them know they had the right to refuse publication. Informed consent for participation was obtained from every patient.

\section{Patient consent for publication}

Informed consent for publication of images and data was obtained from every patient including the patient described in the case report.

\section{Competing interests}

The authors declare that they have no competing interests.

\section{References}

1. Sarrión Pérez MG, Bagán JV, Jiménez Y, Margaix M and Marzal C: Utility of imaging techniques in the diagnosis of oral cancer. J Craniomaxillofac Surg 43: 1880-1894, 2015.

2. Deepho C, Watanabe H, Kotaki S, Sakamoto J, Sumi Y and Kurabayashi T: Utility of fusion volumetric images from computed tomography and magnetic resonance imaging for localizing the mandibular canal. Dentomaxillofac Radiol 46: 20160383, 2017.

3. Kakimoto N, Chindasombatjaroen J, Tomita S, Shimamoto H, Uchiyama Y, Hasegawa Y, Kishino M, Murakami S and Furukawa S: Contrast-enhanced multidetector computerized tomography for odontogenic cysts and cystic-appearing tumors of the jaws: Is it useful? Oral Surg Oral Med Oral Pathol Oral Radiol 115: 104-113, 2013.

4. Todorovic VS, Postma TC and van Zyl AW: Assessment of the anterior loop of the inferior alveolar nerve using reformatted computed tomography: A retrospective study. Br J Oral Maxillofac Surg 56: 186-191, 2018.

5. Baba A, Goto TK, Ojiri H, Takagiwa M, Hiraga C, Okamura M, Hasegawa S, Okuyama Y, Ogino N, Yamauchi $\mathrm{H}$, et al: CT imaging features of antiresorptive agent-related osteonecrosis of the jaw/medication-related osteonecrosis of the jaw. Dentomaxillofac Radiol 47: 20170323, 2018.

6. Waterbrook AL, Manning MA and Dalen JE: The significance of incidental findings on computed tomography of the chest. J Emerg Med 55: 503-506, 2018.

7. Beheshtian E, Sahraian S, Yousem DM and Khan MK: Incidental findings on cervical spine computed tomography scans: Overlooked and unimportant? Neuroradiology 60: 1175-1180, 2018.

8. Casselden E, Sheerin F and Winter SC: Incidental findings on 18-FDG PET-CT in head and neck cancer. A retrospective case-control study of incidental findings on 18-FDG PET-CT in patients with head and neck cancer. Eur Arch Otorhinolaryngol 276: 243-247, 2019.

9. Hoang JK, Hoffman AR, González RG, Wintermark M, Glenn BJ, Pandharipande PV, Berland LL and Seidenwurm DJ: Management of incidental pituitary findings on CT, MRI, and 18F-fluorodeoxyglucose PET: A white paper of the ACR incidental findings committee. J Am Coll Radiol 15: 966-972, 2018.

10. Jin J and McHenry CR: Thyroid incidentaloma. Best Pract Res Clin Endocrinol Metab 26: 83-96, 2012.

11. Yoon DY, Chang SK, Choi CS, Yun EJ, Seo YL, Nam ES, Cho SJ, Rho YS and Ahn HY: The prevalence and significance of incidental thyroid nodules identified on computed tomography. J Comput Assist Tomogr 32: 810-815, 2008.

12. Shetty SK, Maher MM, Hahn PF, Halpern EF and Aquino SL: Significance of incidental thyroid lesions detected on CT: Correlation among CT, sonography, and pathology. Am J Roentgenol 187: 1349-1356, 2006.
13. Tanpitukpongse TP, Grady AT, Sosa JA, Eastwood JD Choudhury KR and Hoang JK: Incidental thyroid nodules on CT or MRI: Discordance between what we report and what receives workup. Am J Roentgenol 205: 1281-1287, 2015.

14. Sugianto I, Yanagi Y, Konouchi H, Hisatomi M, Okada S, Bamgbose BO and Asaumi J: Incidental finding of papillary thyroid carcinoma on CT examination of mandibular lesion: Case report. Mol Clin Oncol 8: 183-187, 2018.

15. Popovenic G and Jonklaas J: Thyroid nodules. Med Clin North Am 96: 329-349, 2012.

16. Masafumi K and Shinichi S: Japan Association of Breast and Thyroid Sonology. Thyroid ultrasound-a guidebook for diagnosis and management (3rd edition). Nankodo, Tokyo, 2016 (In Japanese).

17. Asaumi JI, Hisatomi M, Yanagi Y, Unetsubo T, Maki Y, Matsuzaki H, Honda Y and Konouchi H: Evaluation of panoramic radiographs taken at the initial visit at a department of paediatric dentistry. Dentomaxillofac Radiol 37: 340-343, 2008.

18. Alves N, Deana NF and Garay I: Detection of common carotid artery calcifications on panoramic radiographs: Prevalence and reliability. Int J Clin Exp Med 7: 1931-1939, 2014.

19. O'Sullivan JW, Muntinga T, Grigg S and Ioannidis JPA: Prevalence and outcomes of incidental imaging findings: Umbrella review. BMJ 361: k2387, 2018.

20. Makdissi J, Pawar RR, Radon M and Holmes SB: Incidental findings on MRI of the temporomandibular joint. Dentomaxillofac Radiol 42: 20130175, 2013.

21. Yanagi Y, Asaumi J, Maki Y, Murakami J, Hisatomi M, Matsuzaki H, Konouchi H, Honda Y and Kishi K: Incidentally found and unexpected tumors discovered by MRI examination for temporomandibular joint arthrosis. Eur J Radiol 47: 6-9, 2003.

22. Kim EK, Park CS, Chung WY, Oh KK, Kim DI, Lee JT and Yoo HS: New sonographic criteria for recommending fine-needle aspiration biopsy of nonpalpable solid nodules of the thyroid. Am J Roentgenol 178: 687-691, 2002.

23. Kang HW, No JH, Chung JH, Min YK, Lee MS, Lee MK, Yang JH and Kim KW: Prevalence, clinical and ultrasonographic characteristics of thyroid incidentalomas. Thyroid 14: 29-33, 2004.

24. Papini E, Guglielmi R, Bianchini A, Crescenzi A, Taccogna S, Nardi F, Panunzi C, Rinaldi R, Toscano V and Pacella CM: Risk of malignancy in nonpalpable thyroid nodules: Predictive value of ultrasound and color-Doppler features. J Clin Endocrinol Metab 87: 1941-1946, 2002.

25. Nam-Goong IS, Kim HY, Gong G, Lee HK, Hong SJ, Kim WB and Shong YK: Ultrasonography-guided fine-needle aspiration of thyroid incidentaloma: Correlation with pathological findings. Clin Endocrinol (Oxf) 60: 21-28, 2004.

26. Iannuccilli JD, Cronan JJ and Monchik JM: Risk for malignancy of thyroid nodules as assessed by sonographic criteria: The need for biopsy. J Ultrasound Med 23: 1455-1464, 2004.

27. Hoang JK, Langer JE, Middleton WD, Wu CC, Hammers LW, Cronan JJ, Tessler FN, Grant EG and Berland LL: Managing incidental thyroid nodules detected on imaging: White paper of the ACR incidental thyroid findings committee. J Am Coll Radiol 12: 143-150, 2015.

28. Haugen BR, Alexander EK, Bible KC, Doherty GM, Mandel SJ, Nikiforov YE, Pacini F, Randolph GW, Sawka AM, Schlumberger M, et al: 2015 American thyroid association management guidelines for adult patients with thyroid nodules and differentiated thyroid cancer: The american thyroid association guidelines task force on thyroid nodules and differentiated thyroid cancer. Thyroid 26: 1-133, 2016.

29. Gharib H, Papini E, Garber JR, Duick DS, Harrell RM, Hegedüs L, Paschke R, Valcavi R and Vitti P; AACE/ACE/AME Task Force on Thyroid Nodules: American association of clinical endocrinologists, american college of endocrinology, and associazione medici endocrinologi medical guidelines for clinical practice for the diagnosis and management of thyroid nodules-2016 update. Endocr Pract 22: 622-639, 2016.

30. Hall FM: Guidelines for management of thyroid nodules. J Am Coll Radiol 12: 655-656, 2015.

31. Wiest PW, Hartshorne MF, Inskip PD, Crooks LA, Vela BS, Telepak RJ, Williamson MR, Blumhardt R, Bauman JM and Tekkel M: Thyroid palpation versus high-resolution thyroid ultrasonography in the detection of nodules. J Ultrasound Med 17: 487-496, 1998.

32. Carroll BA: Asymptomatic thyroid nodules: Incidental sonographic detection. AJR Am J Roentgenol 138: 499-501, 1982. 